\title{
Cyberknife fractionated radiotherapy for adrenal metastases: Preliminary report from a multispecialty Indian cancer care center
}

\author{
Trinanjan Basu' ${ }^{1}$, Tejinder Kataria' ${ }^{1}$, Ashu Abhishek ${ }^{1}$, Deepak Gupta ${ }^{1}$, Shikha Goyal1, \\ Shyam S Bisht ${ }^{1}$, Karthick K Payaliappan ${ }^{2}$, Vikraman Subhramani ${ }^{2}$ \\ ${ }^{I}$ Department of Radiation Oncology, Medanta - The Medicity, Gurgaon, Haryana, India \\ ${ }^{2}$ Department of Medical Physics, Medanta - The Medicity, Gurgaon, Haryana, India
}

Received September 14, 2014; Revised October 28, 2014; Accepted November 01, 2014; Published Online November 29,2014

\section{Original Article}

\begin{abstract}
Purpose: Metastasis to adrenal gland from lung, breast, and kidney malignancies are quite common. Historically radiotherapy was intended for pain palliation. Recent studies with stereotactic body radiotherapy (SBRT) including Cyberknife robotic radiosurgery aiming at disease control brings about encouraging results. Here we represent the early clinical experience with Cyberknife stereotactic system from an Indian cancer care center. The main purpose of this retrospective review is to serve as a stepping stone for future prospective studies with non- invasive yet effective technique compared to surgery. Methods: We retrospectively reviewed four cases of adrenal metastases (three: lung and one: renal cell carcinoma) treated with Cyberknife SBRT. X sight spine tracking was employed for planning and treatment delivery. Patients were evaluated for local response clinically as well as with PETCT based response criteria. Results: With a median gross tumor volume of $20.5 \mathrm{cc}$ and median dose per fraction of $10 \mathrm{~Gy}$, two patients had complete response (CR) and two had partial response (PR) when assessed 8-12 weeks post treatment as per RECIST. There was no RTOG grade 2 or more acute adverse events and organs at risk dosage were acceptable. Till last follow up all the patients were locally controlled and alive. Conclusion: Cyberknife SBRT with its unique advantages like non- invasive, short duration outpatient treatment technique culminating in similar local control rates in comparison to surgery is an attractive option. World literature of linear accelerator based SBRT and our data with Cyberknife SBRT with small sample size and early follow up are similar in terms of local control in adrenal metastases. Future prospective data would reveal more information on the management of adrenal metastases.
\end{abstract}

Keywords: Cyberknife; Adrenal Metastases; Local Control; PETCT Response; X Sight Spine Tracking

\section{Introduction}

Metastases to adrenal gland is common, with usual spread from melanomas (50\%), breast and lung cancers (30-40\%), and renal and gastrointestinal primaries (10-20\%). ${ }^{1,2}$ Most often, adrenal metastases are clinically occult due to its rich blood supply. ${ }^{3}$ Adrenal enlargement can be appreciated with computed tomography (CT) and/or ultrasonography. Magnetic resonance imaging and positron emission tomography (PET) can be helpful in differentiating incidental adrenal adenomas from small metastases. Historically, the use of radiotherapy (RT) has been limited to palliation of painful adrenal metastases. ${ }^{4-7}$ Some recent experience suggested that radiotherapy might have a survival benefit also. ${ }^{8}$

Stereotactic body radiotherapy (SBRT) has increasingly been used to treat primary and metastatic disease outside central nervous system. Cyberknife, a robotic radiotherapy system provides unique advantages in terms of frameless non-invasive treatment, high dose precise delivery and real time tumor tracking with orthogonal X rays. ${ }^{9}$ Recent articles especially in lung and liver malignancies showed benefit in terms of clinical control and non-invasive treatment for surgically declined groups. ${ }^{10,11}$ The similar data in adrenal metastases is still rare.

Here, we present the initial experience of treating adrenal metastasis with cyberknife fractionated radiotherapy. This is to the best of our knowledge first ever Indian data reporting outcomes with Cyberknife fractionated radiotherapy in adrenal metastases.

\section{Methods and Materials}

We reviewed all the four cases of adrenal metastasis treated at our center with Cyberknife fractionated radiotherapy till date. All the cases were healthy males (median age 67 years) with primary focus of disease in lung for three and renal for one case. In 2 out of 4 cases, intent of treatment was control of pain 
due to adrenal metastases, while in remaining 2 , it was detected as a part of routine follow up screening. Incidentally in 3 cases it was a solitary metastatic deposit in right adrenal gland only (Table 1). All the metastatic deposit were diagnosed on PETCT scan with SUVmax value more than 2.5 taken as positive in an already biopsy proven primary malignancy as per International literature.

TABLE 1: Patient and disease characteristics.

\begin{tabular}{ll}
\hline \hline Characteristics & Value \\
\hline Number of patients & 4 \\
Gender & Male: 4 \\
Age: & Range: $49-71$ yrs \\
& Median: 67 yrs \\
Primary site & Lung: 3 \\
& Kidney: 1 \\
Metastasis in adrenal gland Right: 3 \\
\\
Symptoms & Left: 1 \\
& Asymptomatic: 2 \\
\hline \hline
\end{tabular}

The patients were evaluated through Institutional tumor board clinic and the options of laparoscopic adrenalectomy and Cyberknife SBRT were discussed. Patients consented for non-invasive procedure and hence Cyberknife SBRT was performed. The emerging data supporting the role of SBRT also motivated this approach. This was a retrospective review and hence data collection approval was taken from Institutional review board.

\section{SBRT technique}

Cyberknife robotic radiosurgery, an innovative stereotactic body radiotherapy (SBRT) delivery technique, was used for treatment in all the cases. Patient immobilization was with full body vacuum cushion with patient lying supine and both hands placed above head with an additional custom made knee rest for pelvic immobilization. Radiotherapy planning images were acquired in Siemens Biograph 64 slice CT scanner. Planning CT scans of $1 \mathrm{~mm}$ thickness were acquired as per protocol in end expiration and end inspiration phases of respiration. Planning images were imported in Multiplan planning system version 4.6.0 (Accuray Incorporated, Sunnyvale, CA, USA) and after co-registration with additional contrast and PET-CT scans, targets were delineated with assistance from an in-house radiologist. Cases were planned for a median dose of $10 \mathrm{~Gy}$ in 2 fractions (range:7-15 Gy) with $75 \%$ isodose coverage for targets (Figure 1).

The dose calculation algorithm used was Ray Tracing and grid size kept at $1 \mathrm{~mm}$. In all the 4 cases, $X$ sight spine tracking was used for planning and delivery as there was $<3-5 \mathrm{~mm}$ spatial variation of adrenal targets in inspiratory and expiratory planning scans and the distance from the spinal cord was $<6$ cms. The median treatment time was 64 minutes (Table 2).

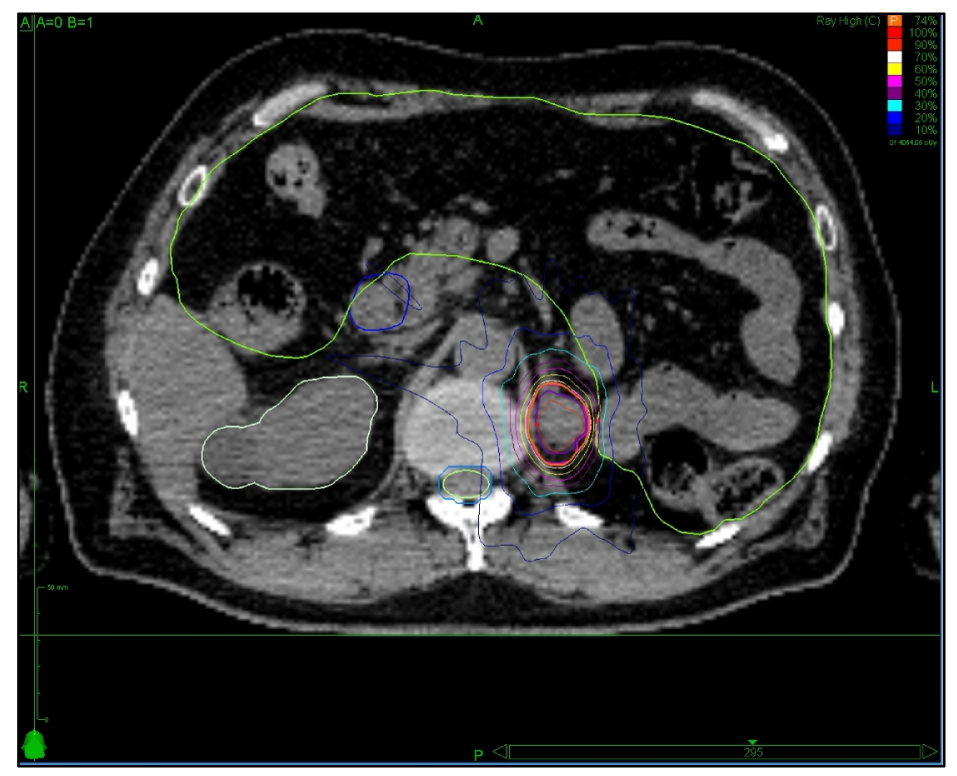

FIG. 1: Axial CT slice with dose distribution.

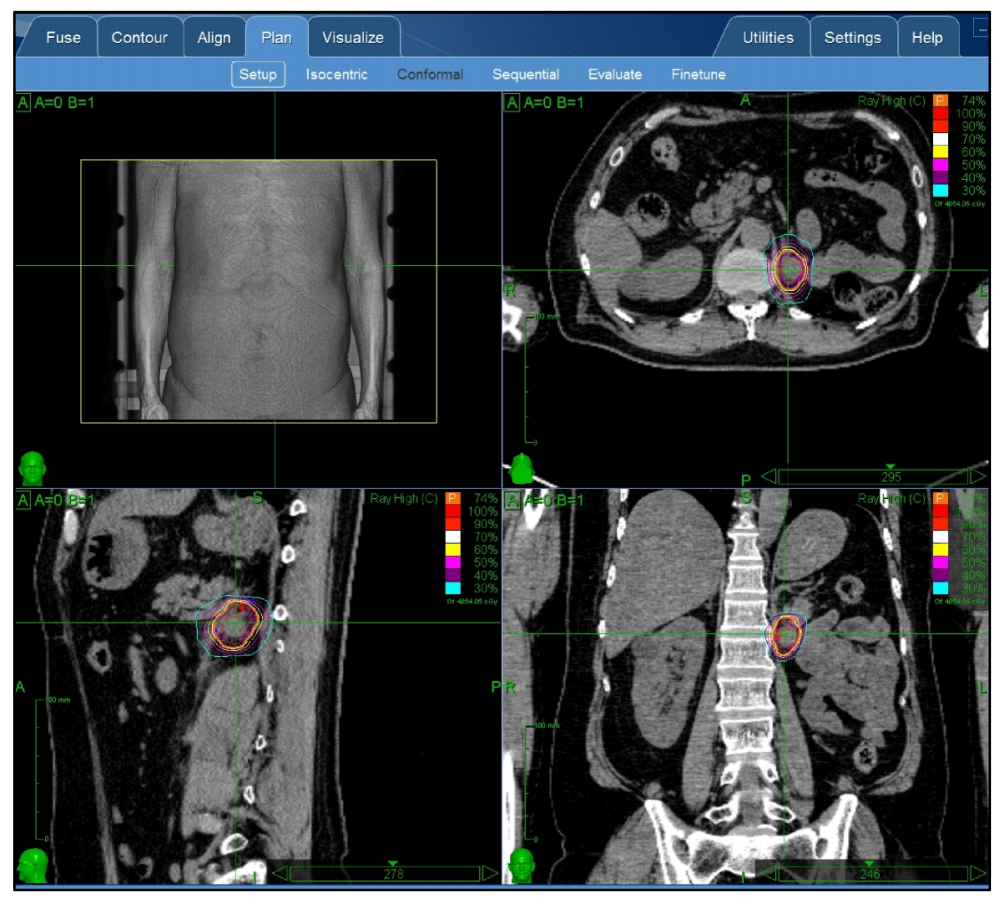

FIG. 2: Isodose distribution in Cyberknife plan.

\section{Evaluation of response}

Patients were followed up for response assessment and clinical evaluation. The evaluation of the response was done using the Response Evaluation Criteria in Solid Tumors (RECIST). The primary endpoints were post Cyberknife response evaluation in terms of local and distant survival. Local failure was defined as progression according to the RECIST criteria. ${ }^{12}$ Survival and control times were calculated from the end of Cyberknife SBRT. All the analyses were done using SPSS version 18.0. 
Since numbers of patients were only four, the basic frequencies were calculated with SPSS and no detail survival analysis was required.

TABLE 2: Technical features.

\begin{tabular}{|c|c|}
\hline Characteristics & Value \\
\hline Adrenal metastasis & $\begin{array}{l}\text { Size (in cm): Median: } 5.1 \\
\text { Range: } 3.2-6.5 \\
\text { Pre therapy PETCT SUVmax: } \\
\text { Median: } 9.66 \\
\text { Range: } 4.7-14.14\end{array}$ \\
\hline Gross tumor volume (GTV) & $\begin{array}{l}\text { Volume (in cc): Median: } 20.5 \\
\text { Range: } 3.6-48.8\end{array}$ \\
\hline Dose per fraction & $\begin{array}{l}\text { Median: } 10 \mathrm{~Gy} \\
\text { Range: } 7-15 \mathrm{~Gy} \\
\text { Mean: } 10.5 \mathrm{~Gy}\end{array}$ \\
\hline $\begin{array}{l}\text { Number of fractions (cybe } \\
\text { knife) }\end{array}$ & $\begin{array}{l}\text { - Range: } 1-3 \\
\text { Median: } 2\end{array}$ \\
\hline Prescription isodose & $\begin{array}{l}\text { Median: } 75 \% \\
\text { Range: } 74-77 \%\end{array}$ \\
\hline Minimum dose to GTV & $\begin{array}{l}\text { Median: } 23.19 \mathrm{~Gy} \\
\text { Range: } 12.1-31.1 \mathrm{~Gy}\end{array}$ \\
\hline Maximum dose to GTV & $\begin{array}{l}\text { Median: } 32.63 \mathrm{~Gy} \\
\text { Range: } 18.7-40.5 \mathrm{~Gy}\end{array}$ \\
\hline Mean dose to GTV & $\begin{array}{l}\text { Median: } 28.5 \mathrm{~Gy} \\
\text { Range: } 15.8-36.7 \mathrm{~Gy}\end{array}$ \\
\hline Treatment time (mins) & $\begin{array}{l}\text { Median: } 64 \\
\text { Range: } 54-69\end{array}$ \\
\hline Tracking method & $\begin{array}{l}\text { X sight spine: } 3 \\
\text { Synchrony: } 1\end{array}$ \\
\hline Number of beams & $\begin{array}{l}\text { Range: } 181-310 \\
\text { Median: } 234\end{array}$ \\
\hline Number of nodes & $\begin{array}{l}\text { Range: } 63-97 \\
\text { Median: } 82\end{array}$ \\
\hline Total MU delivered & $\begin{array}{l}\text { Median: } 29284.07 \\
\text { Range: } 20045.79-36990.72\end{array}$ \\
\hline Ipsilateral kidney dose & $\begin{array}{l}\text { Median of mean: } 3.9 \mathrm{~Gy} \\
\text { Median D20: } 5.3 \mathrm{~Gy} \\
\text { Median D30: } 3.1 \mathrm{~Gy} \\
\text { Range of mean dose:2.8-4.0 Gy }\end{array}$ \\
\hline Spinal cord dose (max dose) & $\begin{array}{l}\text { Median: } 4.6 \mathrm{~Gy} \\
\text { Range Dmax: 3.2-6.6 Gy }\end{array}$ \\
\hline $2 \mathrm{cc}$ & Range: $1.8-3.2 \mathrm{~Gy}$ \\
\hline
\end{tabular}

PET-CT: Positron emission tomography-computed tomographic scan. SUV: Standardized uptake value.

GTV: Gross tumor volume.

MU: Monitor units.

\section{Results}

\section{Patient characteristics}

The primary sites were lung $(\mathrm{n}=3)$ and renal cell carcinoma ( $\mathrm{n}$ = 1). All of them were diagnosed on PETCT scan and the median gross tumor volume (GTV) was $20.5 \mathrm{cc}$ with a median size $5.1 \mathrm{~cm}$ and on diagnostic PET-CT scans the median SUVmax was 9.66. Patients were taken up for 2 fractions with median dose per fraction of $10 \mathrm{~Gy}$.

\section{Toxicity}

No patient developed acute Radiation Therapy Oncology (RTOG) Group Grade 2-4 gastrointestinal, hepatic, renal, or dermatologic toxicity. Mild fatigue was common, as was Grade 1 nausea. Since the median follow up was 6 months no comment could be drawn about late toxicities (Table 3 ).

TABLE 3: Clinical outcome.

\begin{tabular}{ll}
\hline \hline \multicolumn{1}{c}{ Characteristics } & \multicolumn{1}{c}{ Value } \\
\hline $\begin{array}{l}\text { Dimension of metastatic disease on } \\
\text { imaging }\end{array}$ & Pre therapy: Median: $5.1 \mathrm{~cm}$ \\
& Range: $3.2-6.5 \mathrm{~cm}$ \\
& Post therapy: Median: $3.8 \mathrm{~cm}$ \\
& Range: $3.3-4.4 \mathrm{~cm}$ \\
Metabolic parameter of metastatic & Pre therapy SUVmax: Median: \\
disease on PETCT & 9.66 \\
& Range: $4.7-14.14$ \\
& Post therapy SUVmax: Medi- \\
& an: 5.5 \\
& Range: $4.4-6.6$ \\
& CR: 2 \\
Post therapy local response & PR: 2 \\
& Stable: 1 \\
Last follow up overall disease status & Distant disease progression: 3 \\
& Range: $4-10$ months \\
Follow up (FU) duration & Median: 6 months \\
& All 4 patients were alive till \\
& last FU \\
\hline \hline
\end{tabular}

\section{Dose-volume characteristics}

The dose received by the GTV per fraction was between 7-15 Gy per fraction. The minimum, mean and maximum dose received to GTV was noted and the median value was 23.19 , 28.5 and 32.63 Gy respectively. The number of beams used for planning ranged between 181-310 and median number of nodes was 82 . The median monitor units (MU) delivered was 29284.07.

Ipsilateral kidney and spinal cord were found to be the main organs at risk. The median of the mean dose received to ipsilateral kidney was 3.9 Gy while median of D20\% and D30\% were 5.3 and 3.1 Gy respectively. Similarly the median value of the dose max to spinal cord was $4.6 \mathrm{~Gy}$ (Table 2 and Figure 2). 


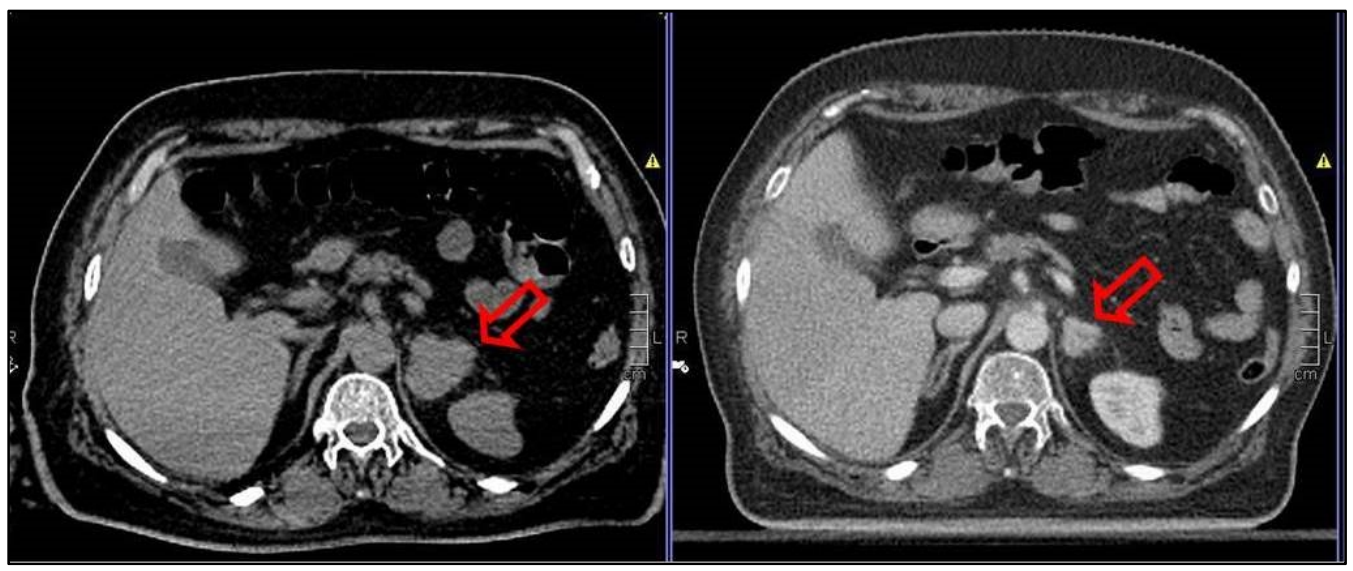

FIG. 3: Pre and post Cyberknife imaging for response assessment.

\section{Clinical outcome}

Between 8-12 weeks after completion of cyberknife treatment patients were evaluated for imaging based response assessment with PETCT scan. The timing of PETCT after SBRT is yet to be validated but most of the SBRT series advocates between 8-12 weeks although post SBRT changes may persists for 24 weeks. ${ }^{13}$ After the therapy median SUVmax on PETCT scan reduced to 5.5 with median tumor size post therapy being $3.8 \mathrm{~cm}$. As per RECIST criteria 2 patients had complete morphologic response with no measurable tumor and no significant SUVmax value and 2 had partial response (Figure 3). With the median follow up of 6 months, all the patients were locally controlled and alive. Unfortunately 3 of them had distant disease progression and were on palliative chemotherapy till last follow up (Table 3).

\section{Discussion}

Adrenal gland has been a common site of metastasis specially from malignancies of lung and kidney. ${ }^{14,15}$ In our small series we had 2 patients diagnosed with adrenal metastasis at presentation and in other 2 it was detected about a year after primary disease treatment. The hypothesis behind treating limited metastatic disease was driven by improved systemic control after successful local treatment. Furthermore aggressive local control can actually prolong disease free survival. ${ }^{16}$, ${ }^{17}$ Oligometastatic tumors may be amenable to SBRT, in contrast to other modalities, especially in circumstances in which patients do not wish to undergo an invasive procedure or are in poor general condition.

The Cyberknife robotic radiosurgery system is an innovative and intelligent tool for SBRT delivery due to couple of reasons. The non-invasive immobilization technique, an inverse treatment planning technique such that the tumor received the maximum dose allowable with the restriction of the maximum normal structure tolerance dose, real time continuous tracking of the target during treatment with two ortho-voltage $\mathrm{X}$ rays and correction before delivery of treatment in real time. All this together with short treatment duration as an outpatient has the potential benefit of better compliance to treatment. The comorbidities and refusal to surgery in these patients warrants delivery of radio therapeutic ablative dosage as a surgical equivalent. The optimal management, although still not standardized however a recent systematic review quoted that stereotactic ablative radiotherapy is a valid alternative in cases when surgery is either refused or not feasible. ${ }^{18}$

Initially radiotherapy for adrenal metastases was intended for palliation, to reduce pain symptoms. A study from the University of Pennsylvania retrospectively reviewed 16 patients treated between 1972 and 1988 with palliative RT for symptomatic adrenal metastases. ${ }^{19}$ The radiation dose was ranged from 29.5-45.0 Gy in 2.5-Gy fractions to $30 \mathrm{~Gy}$ in 3-Gy fractions. The overall response rate was $75 \%$. Six patients achieved complete pain relief with durable remission until death. In a Japanese study, 14 patients, mostly with lung cancer metastasized to the adrenal glands, received palliative RT with a dose of 16-60 Gy, fractionated in 1.6-3 Gy/fraction. The median survival was 3 months, and the 6 -month survival rate was $28.6 \%$ for all patients. ${ }^{20}$

Two recent publications although retrospective, but have analysed the survival data for adrenal metastases treated by SBRT. Chawla et al. reported SBRT for 30 patients treated with a median dose per fraction of $5 \mathrm{~Gy}$, the 1 year survival, local control and distant control rate of $44 \%, 55 \%$ and $13 \%$ respectively. ${ }^{14}$ Another study from University of Florence also highlighted 1 year local control rate of $90 \%$ with SBRT $36 \mathrm{~Gy}$ in 3 fractions. ${ }^{15}$ The published data suggests biological effective dose of greater than $100 \mathrm{~Gy}$ for adequate local control. $^{21}$

In our preliminary experience all the 4 patients were locally disease controlled after Cyberknife SBRT and at response evaluation they had CR or PR. Two patients had abdominal pain requiring narcotic analgesics prior to treatment, were actually pain free after Cyberknife SBRT. In accordance to 
world literature patients actually progressed distantly and developed other new metastatic disease. Here we would emphasise the role of PETCT in initial diagnosis and response evaluation. There are plenty of literature available which established the sensitivity and specificity of PETCT SUVmax value more than 2.5 in a known malignancy with adrenal deposit to be metastatic. ${ }^{22,23}$ In our small series the minimum SUVmax value among the four patients was above 4 .

The benefits of SBRT with Cyberknife in terms of palliation of symptoms, better local control irrespective of primary disease stage or site, non-invasive outpatients department treatment in a short span with minimal acute effects, definitely calls for further evaluation. The advent of ablative radiosurgical dosage achieving similar control rates to surgery warrants prospective randomized data. The shortcomings of our study especially in terms of number of patients and short follow up is well recognized. To the best of our knowledge first ever data from an Indian center with Cyberknife SBRT and also among few early world literature, would actually make path for future clinical trials in treating adrenal metastases with SBRT.

\section{Conclusion}

Cyberknife SBRT with its unique advantages can produce optimal local control for adrenal metastases. The aggressive nature of the primary disease however can result in poor overall survival but the non-invasive and surgical equivalent pain relief and symptom control definitely warrants prospective data on the routine use of Cyberknife SBRT. Till that time with the availability of resource and expertise this modern technique should be used as and when required.

\section{Acknowledgement}

We wish to thank all the authors who have contributed to the final version of the article as well as the technical staff who helped during treatment delivery with Cyberknife.

\section{Conflict of interest}

The authors declare that they have no conflicts of interest. The authors alone are responsible for the content and writing of the paper.

\section{References}

1. Lam KY, Lo CY. Metastatic tumours of the adrenal glands: A 30-year experience in a teaching hospital. Clin Endocrinol (Oxf) 2002; 56:95-101.

2. Wansaicheong G, Goh J. Adrenal metastases; Accessed July 22,103. Emedicine.com. Available from: http://www.emedicine.com/radio/TOPIC17.HTM
3. Kung AW, Pun KK, Lam K, et al. Addisonian crisis as presenting feature in malignancies. Cancer 1990; 65:177-9.

4. Soffen EM, Solin LJ, Rubenstein JH, Hanks GE. Palliative radiotherapy for symptomatic adrenal metastases. Cancer 1990; 65:1318-20.

5. Short S, Chaturvedi A, Leslie MD. Palliation of symptomatic adrenal gland metastases by radiotherapy. Clin Oncol (R Coll Radiol) 1996; 8:387-9.

6. Soejima T, Hirota S, Hishikawa Y, et al. Radiation therapy for adrenal metastases. Nippon Igaku Hoshasen Gakkai Zasshi 1997; 57:801-4.

7. Miyaji N, Miki T, Itoh Y, et al. Radiotherapy for adrenal gland metastasis from lung cancer: report of three cases. Radiat Med 1999; 17:71-5.

8. Oshiro Y, Takeda Y, Hirano S, et al. Role of radiotherapy for local control of asymptomatic adrenal metastasis from lung cancer. Am J Clin Oncol 2011; 34:249-53.

9. Lim CM, Clump DA, Heron DE, Ferris RL. Stereotactic Body Radiotherapy (SBRT) for primary and recurrent head and neck tumors. Oral Oncol 2013; 49:40-6.

10. Yuan ZY, Meng MB, Liu CL, et al. Stereotactic body radiation therapy using the CyberKnife(®) system for patients with liver metastases. Onco Targets Ther 2014; 7:915-23.

11. Bahig H, Campeau MP, Vu T, et al. Predictive parameters of CyberKnife fiducial-less (XSight Lung) applicability for treatment of early non-small cell lung cancer: a single-center experience. Int J Radiat Oncol Biol Phys 2013; 87:583-9.

12. Eisenhauer EA, Therasse P, Bogaerts J, et al. New response evaluation criteria in solid tumours: revised RECIST guideline (version 1.1). Eur J Cancer 2009; 45:228-47.

13. Shang CY, Kasper ME, Kathriarachchi V, et al. Can an alternative backround-corrected [18F] fluorodeoxyglucose (FDG) standard uptake value (SUV) be used for monitoring tumor local control following lung cancer stereotactic body radiosurgery? Int J Cancer Ther Oncol 2014; 2:020317.

14. Chawla S, Chen Y, Katz AW, et al. Stereotactic body radiotherapy for treatment of adrenal metastases. Int J Radiat Oncol Biol Phys 2009; 75:71-5.

15. Casamassima F, Livi L, Masciullo S, et al. Stereotactic radiotherapy for adrenal gland metastases: university of Florence experience. Int J Radiat Oncol Biol Phys 2012; 82:919-23.

16. Oshiro Y, Takeda Y, Hirano S, et al. Role of radiotherapy for local control of asymptomatic adrenal metastasis from lung cancer. Am J Clin Oncol 2011; 34:249-53.

17. Lam KY, Lo CY. Metastatic tumours of the adrenal glands: a 30-year experience in a teaching hospital. Clin Endocrinol 2002; 56:95-101. 
18. Gunjur A, Duong C, Ball D, Siva S. Surgical and ablative therapies for the management of adrenal 'oligometastases' - A systematic review. Cancer Treat Rev 2014; 40:838-46.

19. Soffen EM, Solin LJ, Rubenstein JH, Hanks GE. Palliative radiotherapy for symptomatic adrenal metastases. Cancer 1990; 65:1318-20.

20. Miyaji N, Miki T, Itoh Y, et al. Radiotherapy for adrenal gland metastasis from lung cancer: Report of three cases. Radiat Med 1999; 17:71-5.

21. Onishi $H$, Shirato H, Nagata $Y$, et al. Hypofractionated stereotactic radiotherapy (HypoFXSRT) for stage I non-small cell lung cancer: Updated results of 257 patients in a Japanese multi-institutional study. J Thorac Oncol 2007; 2:S94-100.

22. Cho AR, Lim I, Na II, et al. Evaluation of Adrenal Masses in Lung Cancer Patients Using F-18 FDG PET/CT. Nucl Med Mol Imaging 2011; 45:52-8.

23. $\mathrm{Xu} \mathrm{B}, \mathrm{Gao}$ J, Cui L, et al. Characterization of adrenal metastatic cancer using FDG PET/CT. Neoplasma 2012; 59:92-9. 